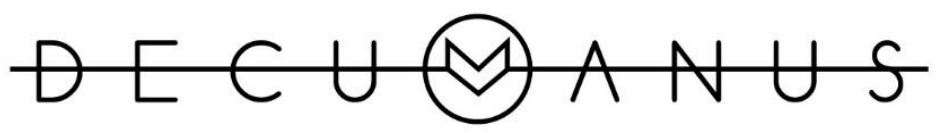

REVISTA INTERDISCIPLINARIA SOBRE ESTUDIOS URBANOS

\title{
“LA OTRA VULNERABILIDAD” MASCULINIDADES Y VIOLENCIA URBANA EN EL ESPACIO PÚBLICO DE CIUDAD JUÁREZ
}

"THE OTHER VULNERABILITY" MASCULINITIES AND URBAN VIOLENCE AT THE CIUDAD JUÁREZ'S PUBLIC SPACE

\author{
Javier Delgado Martínez \\ Vinculación \\ University of Texas at El Paso, Estados Unidos de América \\ E-mail: javierdelgadomtz@gmail.com
}

Primera versión recibida en: 01 de junio, 2016

Última versión recibida en: 29 de septiembre, 2016

\section{Resumen}

Este artículo expone a través de doce entrevistas/historias orales hechas en espacios públicos de Ciudad Juárez en 2015 a hombres mayores de edad y económicamente activos sobre su construcción discursiva en relación a temas como: pobreza, desigualdad, desempleo, crecimiento económico, equipamiento urbano, educación, deserción escolar y su consecuente relación con la masculinidad y la violencia urbana. Se comprueba en los resultados que, en general, son los hombres jóvenes las mayores víctimas de la violencia urbana, es decir, también son vulnerables, pero a la vez son también los mayores perpetradores de ésta debido a que se encuentran en una etapa de construcción de su propia masculinidad, género e identidad. Dicha construcción es influenciada por todos los miembros de la sociedad incluidos sus pares.

Palabras clave: Espacio público, miedo y temor, masculinidades, violencia urbana

\section{Abstract}

This article presents through twelve interviews/oral histories made in public spaces of Ciudad Juarez in 2015 economically active men, about their discursive construction in topics like: Poverty, Inequality, Unemployment, Economic Growth, Urban Equipment, Education, School Dropout and its consequent relation with masculinity and urban violence. It is found at the results that, in general, young men are the main victims of urban violence, meaning that they are vulnerable too, but at the same time, they are the biggest perpetrators of urban violence because they are in a stage of building their own masculinity, gender and identity. In turn, this construction is influenced by all members of society including their peers.

Keywords: Public space, fear, masculinities, urban violence 


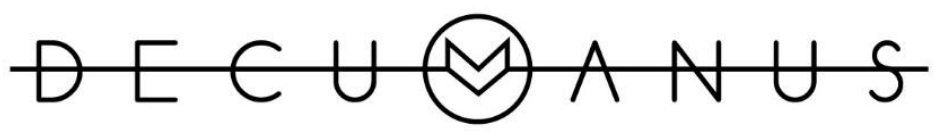

\section{Sumario}

- Introducción

- Inseguridad, miedo y temor al delito

- El espacio público como escenario de violencia

- Masculinidades y violencia

- Jóvenes y violencia

- Violencia juvenil en Ciudad Juárez

- Metodología

- Análisis de datos cuantitativos

- Análisis de datos cualitativos

- Conclusión

- Bibliografía

\section{Introducción}

Hasta hace menos de una década, más de la mitad de la población mundial vive en zonas urbanas, situación que no solo ha traído ventajas como el fácil acceso a los servicios públicos, la movilidad accesible a través de diferentes tipos de transporte público y privado, la cercanía a bienes y servicios y el acceso a espacios de esparcimiento y recreación social, sino que también ha acarreado desventajas como el ruido, la contaminación ambiental, el hacinamiento, la vida acelerada, el estrés y la inseguridad ciudadana. En este último aspecto, la inseguridad ciudadana, encontramos a la violencia urbana entendida para efectos de este documento como aquella perpetrada en el espacio público y sobre el cuerpo de las personas, la cual, se ha convertido en una gran amenaza para el desarrollo de toda ciudad.

Existen diferentes puntos de vista acerca de si la violencia es intrínseca a la ciudad, es decir que 'no hay ciudad sin violencia', y, aunque éste debate ha generado posturas antagónicas, vale la pena afirmar que la violencia en todas sus modalidades ha acompañado al humano desde su origen, ésta se revela como el sujeto principal de su vida y de su historia, se ejerce de forma sistemática, es permitida, normalizada y practicada impunemente por todos los miembros de la sociedad incluyendo al Estado, y los más débiles son casi siempre sus principales víctimas (Silva, 2006).

No existe una causa específica para la violencia, sino que ésta es una relación específica del conflicto que genera un particular tipo de organización espacial (Carrión M., 2008) como puede ser, a 




REVISTA INTERDISCIPLINARIA SOBRE ESTUDIOS URBANOS

través de la proyección de los imaginarios del miedo que se convierten en un elemento constructor de ciudad. Pero, con la violencia no solo se pierde la ciudad sino la ciudadanía, nos dice Briceño León (2007), es decir, los derechos sociales que como ilusión y realidad han representado a la ciudad moderna. El modelo de sociedad actual produce y reproduce violencias resultado de la fragmentación, la exclusión, la densidad poblacional y la disputa por el espacio público y los servicios (Carrión M., 2008); éstas violencias cambian constantemente dependiendo del tiempo y del lugar.

Lamentablemente, la medición de la violencia se ha limitado mayormente a estadísticas de mortalidad; en este sentido, se deja fuera un sinnúmero de factores y elementos que son clave para su entendimiento como lo son: el miedo al delito, la percepción de riesgo y la percepción de amenaza que a su vez se vinculan con la (des)información de los medios de comunicación, convirtiendo a la televisión y ahora al internet en las formas habituales para "estar enterado" de lo que acontece en nuestro entorno. Como resultado observamos que se genera un imaginario geográfico de la violencia, es decir lugares específicos que son considerados como peligrosos ante las personas y aunque no siempre sean éstos donde se cometan la mayor parte de los delitos, de igual manera, emerge un "otro" perpetrador de la violencia urbana, es decir, personificamos al delincuente generalmente como una persona hombre, de bajos recursos, relativamente joven y de aspecto sucio y desaliñado.

El anterior imaginario social de la delincuencia nos sesga de una realidad presentándonos a través de la influencia de los medios de comunicación, de la experiencia vicaria (parientes y amigos) y de la propia, a un personaje estereotipado históricamente como intrépido (carente de miedo y temor) e invulnerable, dominador de la esfera pública y único perpetrador de la violencia: el hombre. Sin embargo, datos estadísticos generados por ejemplo en los Estados Unidos, comprueban que los hombres a diferencia de las mujeres, se encuentran significativamente en un mayor riesgo de ser víctimas del crimen especialmente en el espacio público (Brownlow, 2005). A pesar de ello, sus miedos y sus vulnerabilidades han recibido considerablemente menos atención en el reciente discurso social y académico que lo que han recibido las mujeres. Con frecuencia repetida se ha dado una yuxtaposición de intrepidez y criminalidad entre hombres como únicos perpetradores y, la temerosidad y vulnerabilidad de las mujeres como víctimas principales, pero se ignora la indiscutible evidencia de la victimización masculina y pasa por alto, las complejidades de las vulnerabilidades masculinas no solo en ese país (ibíd.), sino prácticamente en cualquier punto del territorio mundial.

\section{Inseguridad, Miedo y Temor al Delito}

La inseguridad ha sido considerada el centro de las preocupaciones públicas de los latinoamericanos; la medición de la percepción de la inseguridad y el miedo al delito, se han convertido en variables 


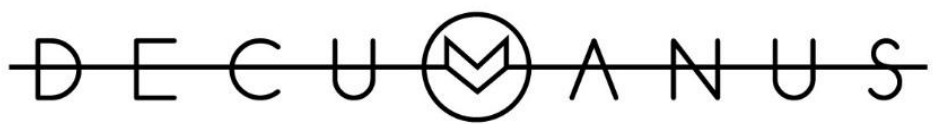

REVISTA INTERDISCIPLINARIA SOBRE ESTUDIOS URBANOS
Núm. 1 Vol. 1. Octubre 2015 - Octubre 2016

Instituto de Arquitectura, Diseño y Arte

Universidad Autónoma de Ciudad Juárez

ISSN: 2448-900X

imprescindibles en los estudios de calidad de vida (Muratori \& Zubieta, 2013). El punto de partida que tenemos, es una amplia y aceptada cantidad de resultados empíricos y propuestas teóricas en diversas investigaciones sobre la inseguridad, la dimensión ambiental del delito y de las denominadas 'paradojas del delito' (Fernández-Ramírez, 2008). Durante mucho tiempo, se asumió que el miedo al delito era la consecuencia de la victimización, entendida esta última como el acto en el cual una persona es objeto del uso de la fuerza que le produce daño físico o psicológico, mientras que el miedo al delito entendido como una percepción y una emoción subjetiva de los ciudadanos (Muratori \& Zubieta, 2013); éste último (el miedo), se ha configurado como un problema en sí mismo, independientemente si se ha sido víctima de un delito o no.

Haber sido víctima de un delito puede conllevar a una serie de consecuencias psicológicas tales como estrés, desordenes postraumáticos y bajos niveles de bienestar, sin embargo, mientras que la victimización no afecta significativamente el bienestar de una persona ni su percepción del clima emocional, sí lo hace directamente a la confianza (Muratori \& Zubieta, 2013). El miedo trasciende las relaciones individuales; numerosos estudios han revelado que el miedo al delito está asociado con una serie de consecuencias tanto a nivel individual como a nivel comunitario, como el empobrecimiento de la salud mental, el desarrollo de cuadros patológicos, las reducciones en el funcionamiento físico, cambios en la conducta, fractura del sentido de comunidad y el abandono de los espacios públicos. El miedo al delito no necesariamente disminuye el bienestar de las personas, es considerado en su lugar, como una defensa natural y adaptativa para hacerle frente al crimen (Muratori \& Zubieta, 2013).

El temor es producto de una percepción de exposición constante a acciones de violencia delictual, es un fenómeno social que manifiesta un peligro para el bienestar colectivo, tiende a reforzar posiciones poco meditadas, no consensuadas y erradas (Oviedo, 1995). El miedo, el temor prolongado y la angustia que produce salir a la calle, de noche o 'dejar la casa sola', conduce muchas veces a la adopción de medidas desafortunadas que pone énfasis en la represión por sobre otras soluciones; ésta presión social que exige el uso de la represión conduce a lo que se conoce como "institucionalización de la violencia" (ibíd.). La excesiva demanda de represión conduce finalmente a una privatización de la vida; la ciudad se encierra, las calles y las plazas quedan sin vida, se deshabitan los lugares públicos por el miedo y el temor a las acciones de violencia.

Con el aumento de los niveles de temor se construye un imaginario que tiende a la indistinción; de esta manera, los que transitan por lugares públicos a ciertas horas y en ciertos días, son vistos como sujetos peligrosos. El delincuente no es reconocible, lo que aumenta la percepción de amenaza; todos los otros aparecen como posibles agresores (Dammert et al., 2004). Así, las diferencias por estratos sociales se manifiestan: si en los estratos bajos se conoce al delincuente (vecinos, parientes, 


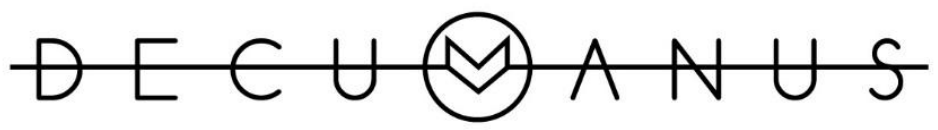

REVISTA INTERDISCIPLINARIA SOBRE ESTUDIOS URBANOS

conocidos del barrio), en los estratos más altos no se le conoce, por lo tanto, la tendencia a la indistinción y a la estigmatización de algunos perfiles es mayor (ibíd.).

Aceptamos pues, que existe una distinción entre el sentimiento difuso de inseguridad que se registra mediante las encuestas masivas de victimización, la reacción emocional (el miedo y el deseo de escape) y ante la posibilidad de sufrir un delito en una situación real (Fernández-Ramírez, 2008). Sabemos que los lugares donde ocurren la mayor parte de los delitos no son los mismos en los que la mayoría siente temor, también sabemos de los modelos ecológicos de territorialidad y control social que han dado lugar a las propuestas de prevención del delito a través del diseño urbano, los modelos oportunistas y el carácter profesional del acto delictivo, la importancia del aspecto físico del abandono y de los lugares con diseños complejos que ofrecen escondites y vías rápidas de escape a los delincuentes (ibíd.).

En este sentido el espacio público (EP) se constituye como un espacio violento, un campo de batalla en el que el otro aparece como amenazante y por lo mismo, la pluralidad no puede desplegarse (Dammert et al., 2004). El temor como experiencia individual muestra diferencias que interseccionan la edad, el sexo y el estrato social. El EP ha implosionado dejando la violencia sustentada en el imaginario del otro amenazante en donde todos los peligros aparecen como posibles (ibíd.). La evidente crisis de lo público entendida como el espacio de la interacción ciudadana, enfrenta al sujeto con un laberinto signado esencialmente por su soledad, especialmente porque su existencia se ve reducida a un estatuto de vida que no ofrece lazos sociales capaces de generar sentido de pertenencia; surge la percepción de amenaza como configuración imaginaria del otro, y la percepción de riesgo en el que el EP aparece derruido, caótico y violento (Dammert et al., 2004).

\section{El Espacio Público como Escenario de Violencia}

"El espacio público es la ciudad", afirmación categórica hecha por Borja y Muxí (2000). El espacio público no es solo un espacio residual entre calles y edificios, tampoco es un espacio vacío considerado público por razones jurídicas, sino que es un espacio físico, simbólico y político a la vez, define la calidad de vida de sus habitantes y la historia de la ciudad que lo contiene (ibíd.). Es ahí en el EP donde la sociedad "desigual y contradictoria" puede expresar sus conflictos y ejercer la ciudadanía; la diversidad tanto de funciones como de usuarios y la continuidad de su uso, hace posible el intercambio entre desiguales bajo un mínimo de pautas comunes de civismo, permite la convivencia mediante una conquista democrática que implica conflicto y riesgo, pero también legitimidad, fuerza acumulada, alianzas y negociación, y lo convierten en un desafío cultural (Borja y Muxí, 2000:20).

EI EP posee un principio ideológico y una retórica dominante: es un espacio abierto a todos y 


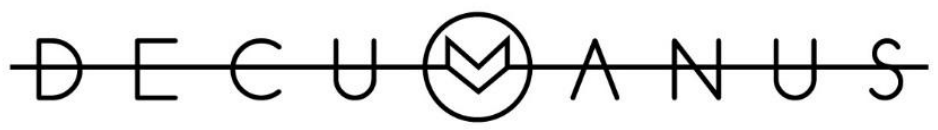

REVISTA INTERDISCIPLINARIA SOBRE ESTUDIOS URBANOS

sin exclusiones, todos somos iguales ante él, independientemente de nuestra posición socio-cultural; pero seguramente, éste espacio no ha existido jamás (Aramburu, 2008). Desde la antigüedad, en el ágora ateniense, espacio público por antonomasia, se restringía el acceso a las mujeres, a los esclavos y a los extranjeros; hoy en día, es restringido de manera sutil y a veces descarada, a indigentes, desadaptados sociales y migrantes, dando como resultado que los encuentros sociales sean cada vez menores, debido por un lado a un repliegue de sociabilidad como consecuencia a una sobre-valoración de la intimidad, y por el otro, a una privatización de la sociabilidad, que hace cada vez más improbable los encuentros entre personas socialmente diferentes (Aramburu, 2008).

Hay un temor al EP conocido como agorafobia urbana (Borja, 1998), ya que el EP ya no es un espacio ni protector ni protegido. Esta enfermedad de clase, es imprescindible para aquellos que viven la ciudad como una oportunidad de supervivencia (pobres, migrantes, indigentes), es producida por la degradación y/o la desaparición de lugares públicos integradores y protectores abiertos a todos (ibíd.). A pesar de esto, la administración pública, propietaria de la facultad del dominio del suelo y garante de su accesibilidad, no puede contrarrestar la dinámica propia de la ciudad y el comportamiento de las personas, cuando éstos crean espacios públicos que jurídicamente no lo son o que no estaban previstos como tales, pero que la ciudadanía los adopta y los adapta como tales; en todo caso afirma Borja (1998), lo que define la naturaleza del EP es su uso y no su estatuto jurídico.

Así, las personas en todo momento ajustan sus comportamientos en público de manera recíproca con los demás mediante pactos que no son implícitamente fijos sino dinámicos, y que se están constantemente renegociando entre las personas con intereses, valores e identidades diversas y cambiantes; tales negociaciones jamás podrán ser sustituidas por normativas o regulaciones administrativas, ya que se perdería toda su vitalidad (Aramburu, 2008). En dichas negociaciones aparece con frecuencia el conflicto, inevitable e incluso necesario para la constante adaptación recíproca de las pautas de convivencia.

\section{Masculinidades y Violencia}

Gran parte del análisis sociológico de la violencia en nuestras sociedades implica que simplemente la violencia es aprendida al atestiguar y experimentar la violencia social; la violencia de nuestro orden social nutre la psicología de la violencia, que, a su vez, refuerza las estructuras sociales, económicas y políticas de la violencia (Kaufman, 1987). Para cada acto de violencia aparentemente individual existe un contexto social; el lenguaje del acto violento, es decir, la forma en que la violencia se manifiesta a sí misma, solo puede ser entendida dentro de cierta experiencia social, y ha sido ampliamente institucionalizada como un medio de resolver conflictos (ibíd.); así, nuestras ciudades, nuestra 


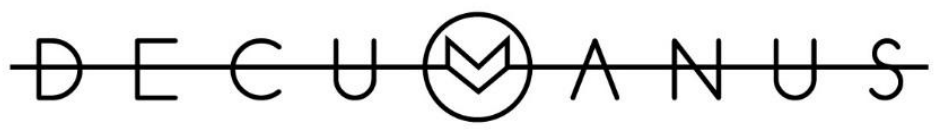

REVISTA INTERDISCIPLINARIA SOBRE ESTUDIOS URBANOS

estructura social, nuestra vida laboral, nuestra relación con la naturaleza y nuestra historia, conforman un escenario donde prevalece la violencia, todo es violencia, violencia codificada e institucionalizada en las estructuras físicas y en las relaciones económicas (ibíd.).

No existe evidencia psicológica, biológica o social que sugiera que los humanos no estamos predispuestos a la agresión o incluso a la violencia; es posible en este sentido que, por cuestión hormonal, el hombre sea biológicamente más agresivo y propenso a la violencia que la mujer, como también es posible una predisposición a la cooperación y a la tranquilidad (Kaufman, 1987). El conflicto siempre es una cuestión de hombres, tal vez, porque son éstos los que han escrito la historia que incluye grandes conflictos, levantamientos armados y genocidio a través de las diferentes culturas y los tiempos, incluso existieron los conflictos en las sociedades cazadoras-recolectoras (ibíd.).

En términos de riesgo, se ha asumido erróneamente que el hombre ha evolucionado para maximizar su longevidad y, a pesar de que la supervivencia y el bienestar son importantes fuerzas motivantes, la perpetración de la especie es uno de los factores determinantes en la vida del hombre, lo que nos indica que, bajo la posibilidad de morir joven, se entienda fácilmente la propensión de éste a involucrarse en comportamientos anti-sociales de alto riesgo (Bribiescas, 2006).

Por ende, existen mitos culturales de masculinidad construidos socialmente como paradigmas. El primero conocido históricamente es aquel que refiere a Dioses y a héroes que actúan como modelos a seguir. El segundo es aquel expresado a través de paradigmas de pensamiento que conlleva a adoptar patrones y reglas de socialización masculina que dictan el cómo los hombres deben conducirse en determinada sociedad bajo estándares y sanciones para aquellos que se atrevan a violar las normas establecidas para formar hombres culturalmente propios (Blazina, 2003).

Por otro lado, la construcción de la identidad de género masculina se encuentra inmersa en una red de procesos políticos y emocionales que son asumidos como reales (Brittan, 1989). Para entender tales procesos es importante observar sus tres énfasis. El primero refiere que la identidad se adquiere mediante la socialización, siendo la diferencia biológica (macho o hembra y/o hombre o mujer) el punto de partida. El segundo refiere a la crisis de masculinidad, que manifiesta que su sentido de lugar en el mundo es retado constantemente por todos los miembros de la sociedad, causando dificultad al tratar de identificarse con los roles propios de la masculinidad, y que cuando éstos se encuentran ausentes, le generan una aguda confusión de género o un problema de psicología masculina. El tercero refiere al modelo de construcción de la realidad, que argumenta que el género no es una forma fija, y de esta manera, la identidad es lo que cada uno demanda ser en ése momento particular del tiempo; la idea de que el género tiene que ser adquirido en lugar de considerarlo como un producto final, va en contra de los dos primeros enfoques (Brittan, 1989). 


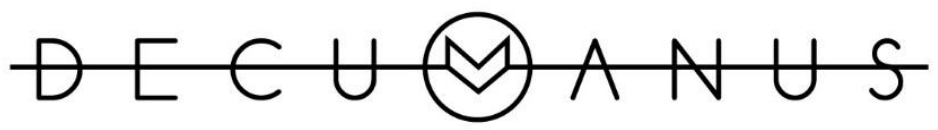

REVISTA INTERDISCIPLINARIA SOBRE ESTUDIOS URBANOS

Así, el hombre sufre de una presión social por parte de todos los miembros de la sociedad para que este construya su identidad masculina, su rol o su género, lo que lo conduce a una gran frustración y a sentimientos de ansiedad y de rabia, endureciéndose o enrudeciéndose, o incluso, rebelándose a las normas sociales no escritas por la sociedad y sus miembros, resultando en la adopción de cualidades blandas o femeninas que le generan des confort, y que a la misma vez, se le asocia con el fracaso, muchas veces de carácter sexual, de ahí que muchos hombres refieran a su hombría a través de sus genitales (Augustus, 2015).

\section{Jóvenes y Violencia}

Gran parte de los estudios en los Estados Unidos sobre la victimización por la violencia sobre todo la que termina con el daño físico o la muerte, revelan que ésta se encuentra asociada con ciertas variables demográficas como la edad, que se constituye como la más importante en la predicción del riesgo de victimización violenta (Cruz, 1999). Otras variables son el sexo, el nivel socioeconómico de la víctima o de la comunidad donde reside, la raza y el grupo étnico de esta. Por ejemplo, en los EU, los hombres, las personas de color, los hispanos, los jóvenes, los pobres y los habitantes del centro de las ciudades, han sido los más vulnerables. Existen otras variables de índole conductual como el consumo de alcohol y la posesión de armas de fuego, su presencia se convierte en un factor de riesgo a sufrir una agresión; estas variables se asocian más con el perpetrador de la violencia que con la víctima.

En América Latina, las tendencias parecen ser muy parecidas a las de los EU, salvo algunas variables que no han sido abordadas ampliamente como la raza y la etnia separadas de la cuestión de género. Pertenecer a un estrato socioeconómico bajo suele considerarse un factor de riesgo de victimización violenta, en algunos casos se ha visto que la condición personal de la víctima pesa más que el contexto ambiental en donde el acto se produce (Cruz, 1999).

Mientras la toma de riesgos y las declaraciones de intrepidez e invulnerabilidad son ampliamente practicadas y normativas de la hegemonía masculina, las estadísticas de crimen indican que la distribución del riesgo al crimen violento es altamente desigual; por ejemplo, el número de sentenciados del fuero común o federal a nivel nacional según su sexo, delito consignado y edad en México, arroja una relación de 7\% para mujeres y un 93\% para hombres, 3,882 y 49,155 respectivamente, entre las edades de 18 a 29 (ver Tabla 1). 


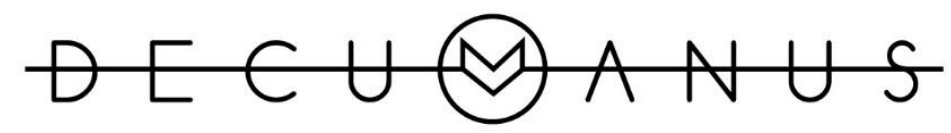

REVISTA INTERDISCIPLINARIA SOBRE ESTUDIOS URBANOS

\begin{tabular}{|l|rr|rr|rr|rr|}
\hline \multirow{1}{*}{ Delito } & \multicolumn{2}{|c|}{18 y 19 años } & \multicolumn{2}{c|}{20 a 24 años } & \multicolumn{2}{c|}{25 a 29 años } & \multicolumn{2}{c|}{ Total } \\
& Hombres & Mujeres & Hombres & Mujeres & Hombres & Mujeres & Hombres & Mujeres \\
\hline Total delito & $\mathbf{8 5 6 0}$ & $\mathbf{5 4 1}$ & $\mathbf{2 1 3 3 4}$ & $\mathbf{1 6 7 1}$ & $\mathbf{1 9 2 6 1}$ & $\mathbf{1 6 7 0}$ & $\mathbf{4 9 1 5 5}$ & $\mathbf{3 8 8 2}$ \\
Robo & 5298 & 310 & 11777 & 800 & 9666 & 690 & 26741 & 1800 \\
Golpes y lesiones & 724 & 76 & 2297 & 356 & 2114 & 410 & 5135 & 842 \\
Robo de vehículo & 516 & 21 & 1228 & 41 & 1137 & 38 & 2881 & 100 \\
Homicidio & 397 & 17 & 1101 & 62 & 994 & 54 & 2492 & 133 \\
Daño bienes ajenos & 208 & 8 & 740 & 73 & 806 & 68 & 1754 & 149 \\
Narcóticos & 259 & 22 & 583 & 33 & 523 & 30 & 1365 & 85 \\
Actos ilícitos & & & & & & & & \\
$\quad$ con armas & 168 & 6 & 487 & 6 & 524 & 13 & 1179 & 25 \\
Violación & 178 & 1 & 431 & 7 & 423 & 1 & 1032 & 9 \\
Abuso sexual & 105 & - & 277 & 3 & 312 & 7 & 694 & 10 \\
Secuestro $^{2}$ & 56 & 7 & 210 & 25 & 195 & 28 & 461 & 60 \\
Otros $^{2}$ & 651 & 73 & 2203 & 265 & 2567 & 331 & 5421 & 669 \\
\hline
\end{tabular}

Tabla 1. Sentenciados de fuero común o federal a nivel nacional según sexo, delito consignado y edad. Fuente: Salazar (2016).

Expresar el miedo es arriesgarse al reto de sus identidades de desarrollo y al deterioro del respeto de los otros; el ignorarlo, es arriesgarse a retar a su seguridad personal o inclusive a algo peor: la muerte (Brownlow, 2005). Sus miedos, son respondidos hacia y manejados desde, una manera que atenta minimizar el riesgo sin comprometer con esto la identidad hegemónica masculina; el macho hegemónico es reconocido discursivamente por prácticas de agresión, intrepidez, fuerza física y emocional, control y por la toma de riesgos, así como aquellas cualidades y características consideradas "no femeninas" que sostienen y reproducen los beneficios materiales del poder patriarcal (ibíd.). Expresiones exageradas y conductas anteriores forman parte del discurso de convertirse en hombre en la sociedad occidental; los adolescentes en particular, comúnmente muestran una fachada de intrepidez y valentía que utilizan para posicionarse e identificarse jerárquicamente a sí mismos, así como para afirmar su autoridad sobre los otros, hombres y mujeres.

Es así como se genera un círculo maligno donde el temor aumenta el abandono de los espacios públicos y a su vez magnifica la percepción ciudadana de inseguridad, se genera un escepticismo generalizado hacia las instituciones públicas especialmente en los jóvenes de la mayoría de los estratos socioeconómicos, éstas (las instituciones) ya no son un referente simbólico para la población (Dammert et al., 2004). Esto genera una sensación de impotencia e impunidad intensa en la población joven que trae aparejado el incremento de grupos sociales que desarrollan sus propias señas de identidad que les dan sentido de pertenencia y protección de grupo, crecen por consecuencia las tribus urbanas, agrupaciones móviles y flexibles que comparten emociones, símbolos e intereses puntuales, pero sin la autoridad y duración necesarias para ofrecer normas y creencias estables (ibíd.). 


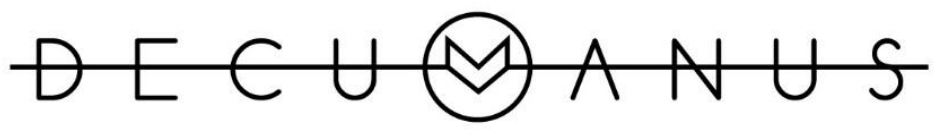

REVISTA INTERDISCIPLINARIA SOBRE ESTUDIOS URBANOS

En este contexto de masculinidad de protesta, la masculinidad marginada adopta temas de la masculinidad hegemónica de la sociedad en general, pero al mismo tiempo se desarrolla en un contexto de pobreza marginal (Brownlow, 2005). Este repertorio de prácticas exageradas y conductas adoptadas por hombres jóvenes marginalizados, dan respuesta a su impotencia, rabia y frustración sobre su exclusión de los dividendos de la masculinidad hegemónica: movilidad restringida, acceso reducido a la buena educación, a los buenos trabajos, a la seguridad económica y a la capacidad de consumo, a los futuros inciertos con mujeres, y especialmente, a las disminuidas perspectivas por alcanzar una identidad masculina culturalmente normativa (Brownlow, 2005).

Influenciados por las condiciones de pobreza, desempleo y un ambiente de violencia, así como envueltos por sentimientos de rabia, miedo y resentimiento, prácticas de agresión, toma de riesgos y competencia, permite que se irrumpa en erupciones violentas; incluso, su exclusión de la esfera económica del normativo desarrollo masculino, sugiere la consiguiente importancia de los espacios públicos como la calle - como lugares para la interpretación de la masculinidad; una geografía que incrementa el riesgo a la vulnerabilidad de éstos jóvenes hacia encuentros violentos. Estas interpretaciones y sus mensajes son comúnmente expresados y retados en los espacios públicos y en los lugares donde tientan al riesgo, y son por consecuencia, vulnerables a una respuesta violenta generalmente por parte de otros jóvenes (pares) en búsqueda de su autoridad masculina (Brownlow, 2005). Superar estos riesgos es un impulso al ego, a la identidad y a la autoridad; trágicamente, sin embargo, muchos de estos encuentros resultan en muertes violentas a una temprana edad.

\section{Violencia Juvenil en Ciudad Juárez}

Para el caso de Ciudad Juárez y como resultado de la disputa por "la plaza" entre cárteles de la droga en la denominada guerra contra el narcotráfico orquestada por el ex-presidente Felipe Calderón Hinojosa, se desató una serie de crímenes violentos contra hombres jóvenes en su mayoría, que dejó a muchos de ellos en la muerte, fenómeno que algunos autores denominaron juvenicidio y algunos otros pocos se atrevieron a llamar masculinicidio, en contraste con el término establecido de feminicidio, ya que apuntaba principalmente a hombres jóvenes, inmersos en el crimen organizado por gusto o por necesidad, o incluso forzados a pertenecer a las filas de la ilegalidad y el crimen como sicarios o halcones ${ }^{1}$, y que llegó a alcanzar el 95\% de los asesinatos cometidos en esos años (Cruz Sierra, 2011).

En Ciudad Juárez, la violencia social agigantada que se dio a partir de 2008 ha tenido como

\footnotetext{
${ }^{1}$ Halcón es el nombre que se les da a jóvenes pagados por narcotraficantes cuya labor es la de vigilar y en su caso alertar a sus jefes por diferentes medios creativos y tecnológicos sobre la posible presencia de grupos rivales o policiacos.
} 


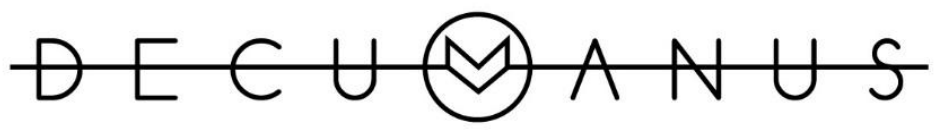

REVISTA INTERDISCIPLINARIA SOBRE ESTUDIOS URBANOS

principales víctimas a hombres jóvenes y pobres, narcomenudistas, drogadictos, pandilleros, sicarios y criminales, es decir, una masculinidad subordinada y estigmatizada que habla de su exclusión social, de su marginación y por consecuencia, de su vulnerabilidad (Cruz Sierra, 2014). Lo anterior alteró la dinámica de vida de la población en general, pero particularmente transformó las agrupaciones de barrio y su relación con el territorio y la identidad. En este proceso de hacerse hombre en la calle, llevó a los jóvenes a experimentar lo que Cruz Sierra (2011) denomina "actos performativos de masculinidad", actos sociales repetitivos que les generan una ilusión de uniformidad y pertenencia, prácticas violentas materializadas regularmente en el cuerpo de los jóvenes.

Esta situación puede plantearse según Cruz Sierra (2014), como el resultado transgeneracional de un cúmulo de violencias que aglutina diversos espacios, instituciones, relaciones y tiempos sociales que se van entretejiendo y desencadenan una serie de empalmes y efectos en poblaciones y relaciones sociales como la de Ciudad Juárez en particular. Dentro del entreverado de violencias acumuladas que vivieron y siguen viviendo estos jóvenes juarenses, se entretejen y amalgaman la violencia intrafamiliar, conflictos entre pares, vida y contiendas de calle, hostigamiento policiaco y algunas otras instituciones como la escuela, la avidez por el consumo de ropa, automóviles, tecnologías, drogas y alcohol, conflictos de noviazgo y sexualidad entre muchas otras; este nudo de violencias va adquiriendo presencia en la experiencia de manera particular en los niños y en su disposición en la construcción de su identidad masculina (Cruz Sierra, 2014:614). Uno de los efectos inmediatos de dicha violencia además de la perplejidad y del dolor por la forma sádica en que mueren familiares, amistades o vecinos, fue reconfigurar las formas de socialidad de los hombres jóvenes y, con ello, replantear las prácticas performativas del ejercicio de la masculinidad ${ }^{2}$ que tradicionalmente se reproducían como parte de la cultura de género (ibíd.).

La categoría "hombre joven" es producto de la intersección del género, de la sexualidad, de la clase, de la etnia y de la edad, y tiene como eje articulador - el poder; dichas categorías se entrecruzan y se asocian con atributos que, en conjunto, se amalgaman y diluyen en un ejercicio cotidiano del 'hacerse hombre en el mundo de la calle, de la pandilla, de la banda y del grupo de pares; proceso siempre inconcluso que tiene sus bases en los lazos primarios del infante con las figuras paterna y materna (comúnmente ausentes), y se engrosa con la precariedad y la penuria económica, social y cultural en la que estos niños nacieron y crecieron (Cruz Sierra, 2014:615).

\section{Metodología}

\footnotetext{
2 El concepto de prácticas performativas del ejercicio de la masculinidad lo propongo a partir del planteamiento de Judith Butler (1990) sobre los actos de representación y constitución del género (Cruz Sierra, 2014).
} 


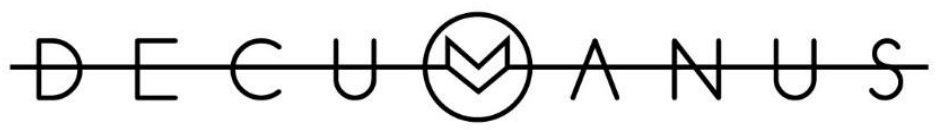

REVISTA INTERDISCIPLINARIA SOBRE ESTUDIOS URBANOS

Con el objetivo de conocer las vivencias de la población masculina, mayor de edad, económicamente activa en Ciudad Juárez y su relación con la percepción que tienen acerca de su propia vulnerabilidad en ser violentado al salir a la calle, es decir, al utilizar el espacio público, se realizaron doce entrevistas/historias orales.

El criterio para seleccionar cuales espacios públicos dentro de la ciudad serían los adecuados, y por consecuencia los lugares para realizar las entrevistas, se tomó como base la reciente publicación: "Bienestar y Seguridad en Ciudad Juárez, Atlas de las Condiciones de vida y convivencia de sus habitantes, 2014", realizado por el Observatorio Ciudadano de Prevención, Seguridad y Justicia de Chihuahua, A.C. El reporte anterior analizó seis delitos de los cuales solo se tomaron tres para efectos de esta investigación, dichos delitos son: robo a transeúnte, homicidio doloso y lesión dolosa, mismos que fueron seleccionado precisamente porque son perpetrados en el espacio público (Ver Mapas 1,2 y 3$)$.

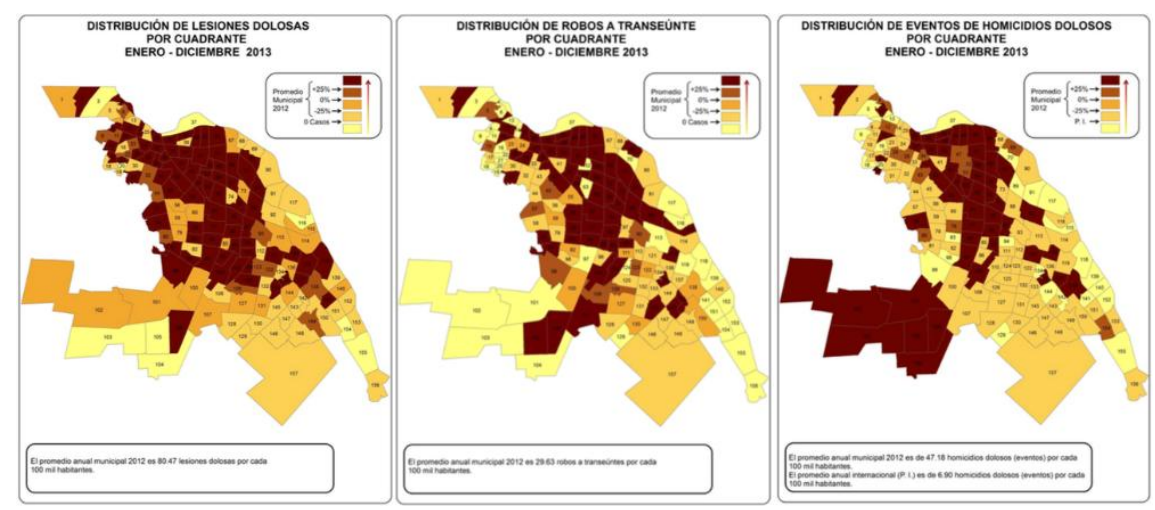

Mapas 1,2 y3: Distribución por cuadrante de Robos a transeúnte, homicidios dolosos y lesiones dolosas respectivamente. Fuente: Bienestar y Seguridad en Ciudad Juárez, Atlas de las condiciones de vida y convivencia de sus habitantes, 2014.

De igual manera, el reporte dividió a la ciudad en 157 cuadrantes de los cuales solo seleccionaron 147 por tener una población superior a los mil habitantes. De los 147 restantes, el reporte analizó 33 cuadrantes de forma preliminar de acuerdo a las altas tasas de delitos y al lugar de residencia de los internos de los CERESOS (Centros de Readaptación Social) del estado. Podemos ver por ejemplo en el Mapa 4 la concentración espacial de los delitos de alto impacto analizados en la ciudad en 2013 y su distribución por cuadrantes. 


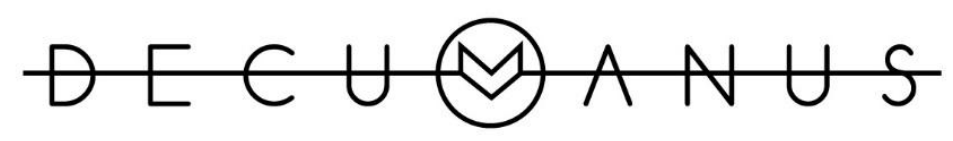

REVISTA INTERDISCIPLINARIA SOBRE ESTUDIOS URBANOS

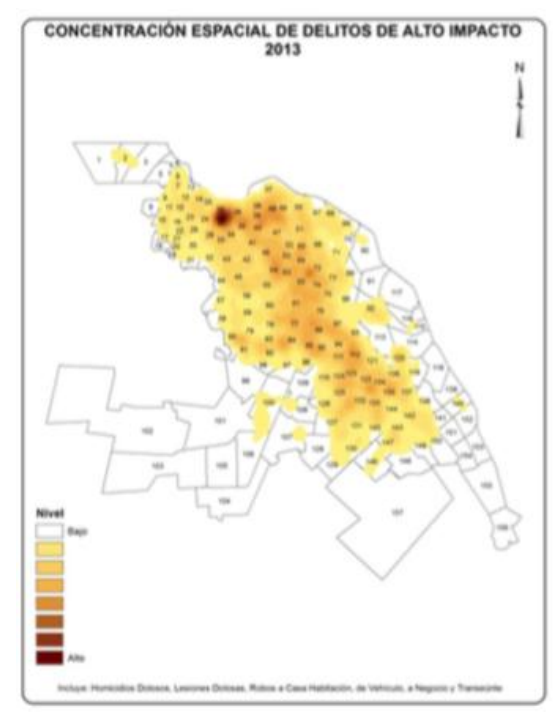

Mapa 4. Concentración espacial de delitos de alto impacto. Fuente: Bienestar y Seguridad en Ciudad Juárez, Atlas de las condiciones de vida y convivencia de sus habitantes, 2014.

De esta manera y con el objetivo de tener un parteaguas para comenzar las entrevistas, se elaboró una tabla que permitiera partir en algún punto(s) de la ciudad pero que a su vez cumpliera con ciertos requisitos en su selección. Se elaboró una tabla conteniendo los cuadrantes con mayor índice delictivo de la ciudad en el periodo Enero-diciembre 2013, se empataron tales cuadrantes y se seleccionaron aquellos que fueran comunes entre los tres eventos (robo a transeúntes, homicidios dolosos y lesiones dolosas).

Así, surge la Tabla 2 en la cual se concentran 26 cuadrantes relacionados con su ubicación geográfica (Centro, Universidad, Oriente, Sur y Valle); también, marcados en rojo aquellos cuadrantes los cuales tuvieron una variación a la alta en delitos de alto impacto con respecto al periodo anterior (2012).

Tabla 2. Elaboración propia con datos de: Bienestar y Seguridad en Ciudad Juárez, Atlas de las condiciones de vida y convivencia de sus habitantes, 2014. 

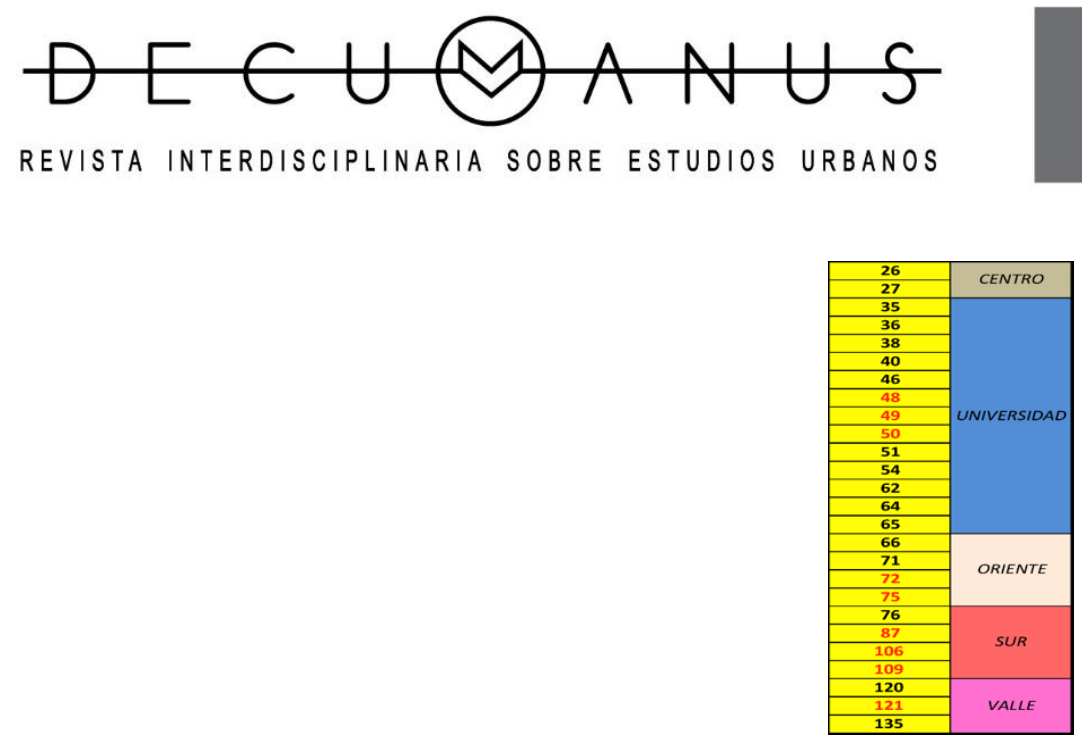

Esto permitió comenzar las entrevistas en los espacios que fuesen los de mayor impacto (Ver Mapa 5).

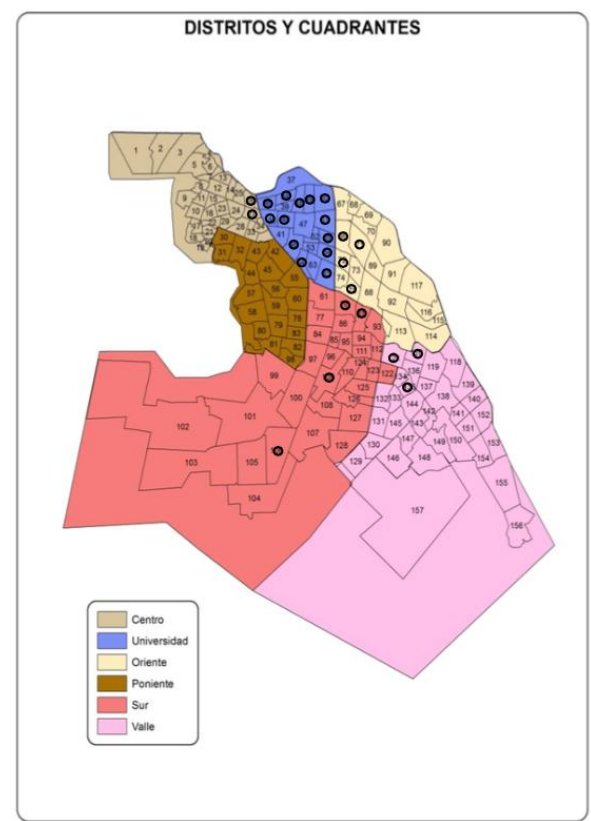

Mapa 5. Ubicación de cuadrantes seleccionados para realizar entrevistas. Elaboración propia en base a mapa elaborado por: Bienestar y Seguridad en Ciudad Juárez, Atlas de las condiciones de vida y convivencia de sus habitantes, 2014.

A manera de ejemplo, se muestra el cuadrante 48 (ver mapa 6), ubicado en la zona denominada Universidad. Comprende las colonias Córdova Américas, Patricia, Los Naranjos, Mayorga, Los Olmos, Miguel Auza, La Playa y El Pronaf. Podemos observar por ejemplo que en el cruce de las avenidas Hermanos Escobar y Abraham Lincoln, se encuentre el punto de mayor concentración espacial en delitos de alto impacto. Ahí se realizó la entrevista al chiclero (narrativa analizada más adelante). 


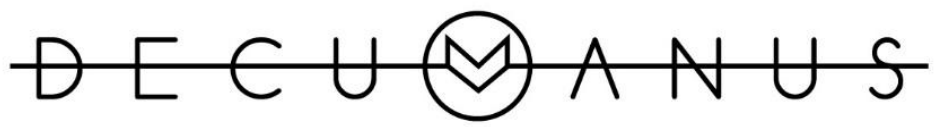

Posteriormente, se elaboró un criterio de entrevista tomando en cuenta las variables que el reporte hecho por el Observatorio Ciudadano tomó en cuenta en relación a los factores económico-sociales y su relación con la criminalidad.

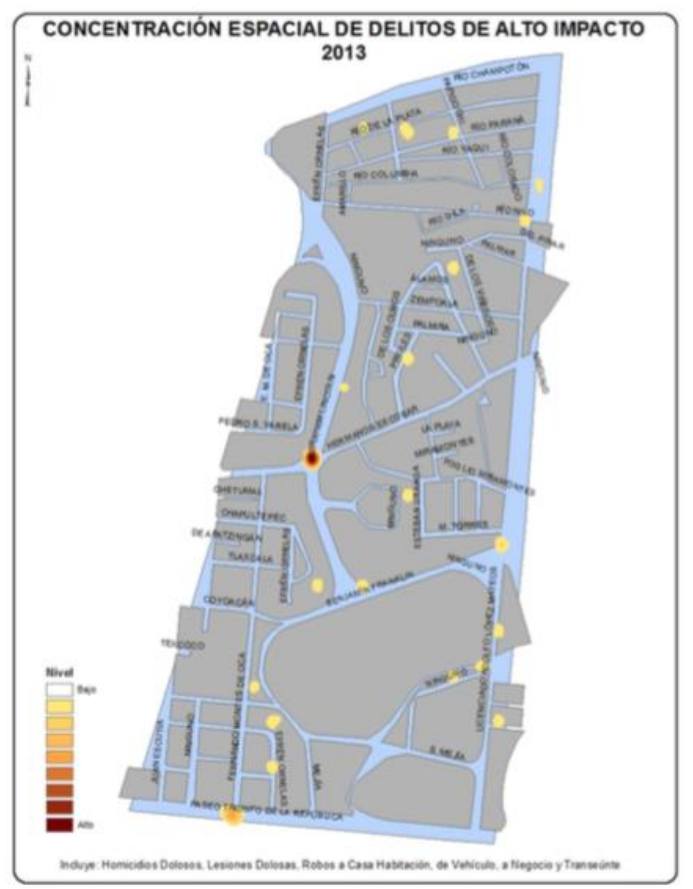

Mapa 6. Concentración de delitos de alto impacto 2013. Fuente: Bienestar y Seguridad en Ciudad Juárez, Atlas de las condiciones de vida y convivencia de sus habitantes, 2014.

La pobreza como primer factor y según el reporte nos dice que la mayoría de los estudios que ellos revisaron plantean una relación positiva entre pobreza y delincuencia, es decir, en presencia de la pobreza encontramos regularmente la delincuencia. La desigualdad, conceptualizada como una distribución inequitativa del ingreso, resulta de igual manera ligada ampliamente con la criminalidad. Concluyen en este sentido que pobreza y desigualdad inciden de manera importante en homicidios registrados. El desempleo por otra parte, describe también una relación positiva con la delincuencia. En contraste, el crecimiento económico plantea una relación negativa con la delincuencia, es decir a mayor crecimiento económico menor delincuencia. En este sentido, se propone una relación positiva entre cantidad de comercio y delito porque al aumentar el comercio, aumentarían las probabilidades de delinquir. Por otro lado, el factor urbano que en este caso lo denomino equipamiento urbano, nos dice que los niveles más altos de crímenes y de violencia se dan en entornos urbanos degradados y aunque no es una relación meramente causal, sí se considera que influye y por lo tanto se incluyó como parte de los temas abordados en la entrevista. La educación entendida como años de escolaridad, tendría una relación negativa con la delincuencia, es decir a mayor escolaridad se 




REVISTA INTERDISCIPLINARIA SOBRE ESTUDIOS URBANOS

disminuye la probabilidad de conductas delictuales. Por último, la deserción escolar es un factor determinante en la probabilidad de cometer actos delictivos.

Se hicieron las revisiones pertinentes al formato de entrevista y a manera de piloto se realizaron tres entrevistas para conocer los resultados para saber si estos eran los esperados al inicio del estudio. Finalmente se elaboraron doce entrevistas/historias orales a los personajes denominados dada su actividad o procedencia al momento de la entrevista (vendedor de dulces, parquero, deportado, Zacatecas, abuelo, ingeniero, policía, chiclero, payaso, guardia, estudiante y profesionista), mismos que fueron avisados que el objetivo de la entrevista era estrictamente académico y que no era necesario el que facilitaran un nombre, dirección o cualquier otro dato que los pudiese hacer sentir comprometidos.

Para efectos de evitar hacer sentir molestia al entrevistado y en base a la experiencia que las entrevistas piloto arrojaron, se comenzó el diálogo con un: dígame, como es un día normal en su vida, desde que se levanta por la mañana hasta que vuelve a acostarse por la noche. De esta manera, se pudo crear confianza en el entrevistado a grado tal que prácticamente sin pedirlo, ellos mismos me hacían partícipe de sus experiencias personales, incluso algunas de ellas en temas delicados. Las entrevistas variaron dependiendo del entrevistado entre los 10:37 minutos hasta los 38:53 minutos de duración, tendiendo en promedio a los treinta minutos. Cabe mencionar que se trató de dejar hablar libremente al entrevistado, con la intención de obtener la mayor información posible del mismo; de igual manera, tampoco se perdió el hilo de la entrevista al introducir cada una de las preguntas establecidas previamente (ver Tabla 3) al momento que era propicio para hacerla, dejando como consecuencia que no todas las preguntas se formularon a todos los entrevistados.

Una vez hechas cada una de las entrevistas/historias orales, se continuó con la transcripción de cada una de ellas en el menor tiempo posible posterior a su conclusión, esto con la intención de no perder la esencia y el ánimo percibido a raíz de la experiencia etnográfica. Posteriormente, se volvieron a analizar las entrevistas con la intención de encontrar los puntos clave que ligados con la literatura, dieran la pauta para el desarrollo de la investigación (análisis cuantitativo y cualitativo). Se hizo un empate entre las experiencias de vida de los entrevistados, la(s) teoría(s) que se asocian con cada apartado, el(los) autor(es) que dan sustento a la teoría y el enfoque pretendido.

\section{Análisis de los Datos Cuantitativos}

Para efectos de tener una perspectiva cuantitativa en términos de empate, contienda o contraste en la respuesta a las preguntas hechas, se generó una tabla en hoja de cálculo con el fin de asociar de 


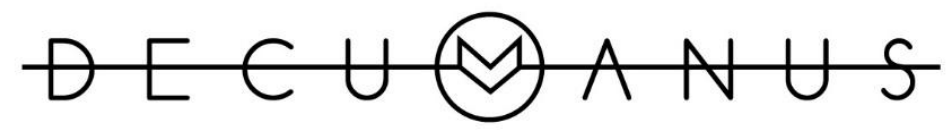

REVISTA INTERDISCIPLINARIA SOBRE ESTUDIOS URBANOS

manera visual y acotada dicha relación, empates [en verde], contiendas [en naranja] y contrastes [en azul] (Ver Tabla 3).

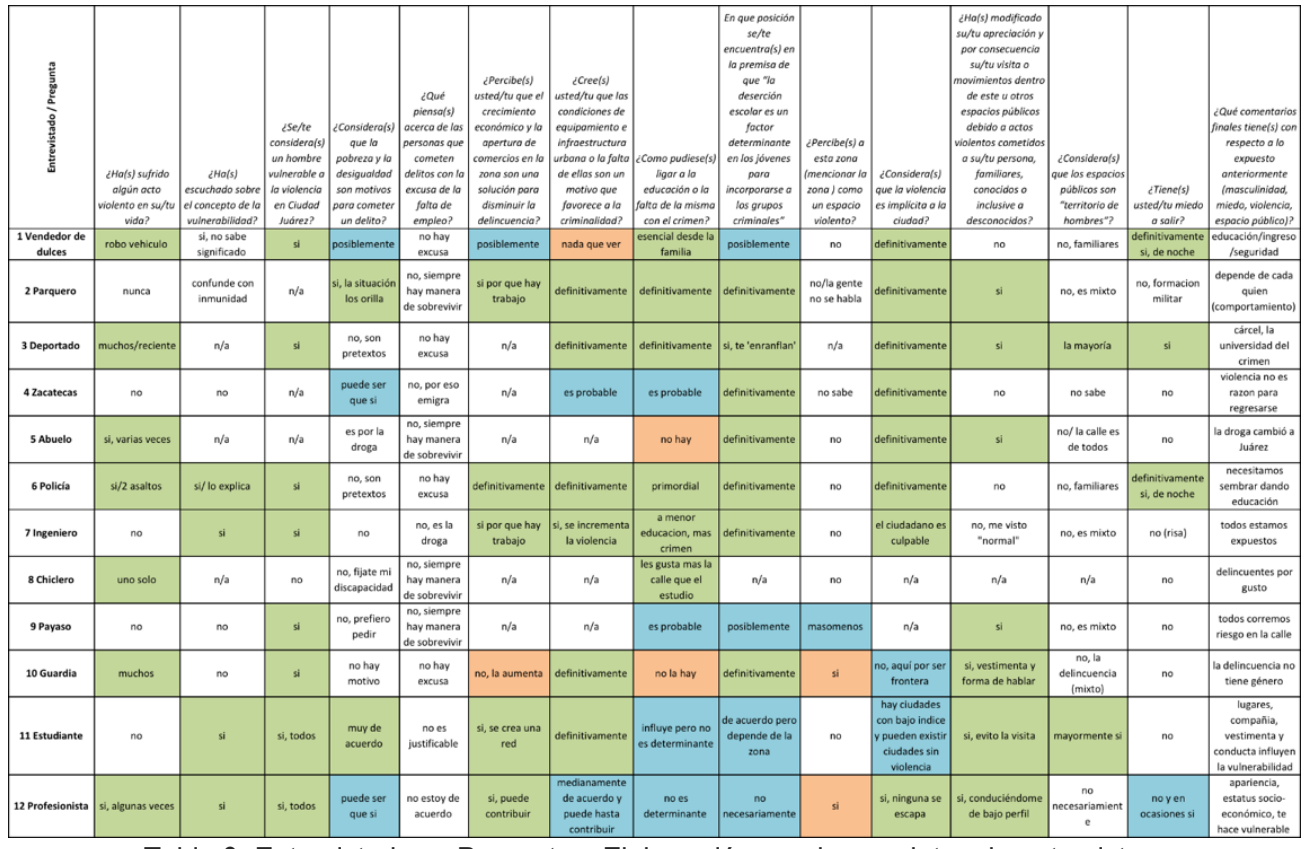

Tabla 3: Entrevistados y Preguntas. Elaboración propia con datos de entrevistas.

Los resultados de entrevistas fueron: cuando se les cuestionó si habían sufrido algún acto violento en su vida el 58\% de los entrevistados manifestó haber sufrido por lo menos uno. Al preguntárseles si habían escuchado el término vulnerabilidad solo el 33\% de los casos contestó afirmativamente. En contraste con la pregunta anterior, al cuestionarlos si se sentían un hombre vulnerable ante la violencia en CJ, el $67 \%$ de ellos mismos contestó afirmativamente, lo que denota que al unir una palabra desconocida con el término violencia, éste cambia de sentido ante los entrevistados.

Cuando se les hizo pensar acerca de la relación existente entre pobreza y desigualdad y la comisión de delitos, dos entrevistados manifestaron que sí existe razón en tal relación, y tres de ellos (25\%), consideraron como probable el cometer un delito ante la vivencia en pobreza y desigualdad. En este mismo tenor se les preguntó qué pensaban acerca de si la falta de empleo es pretexto para algunos a cometer algún tipo de delito, contrastando con las respuestas anteriores en la que en este caso ninguno de los entrevistados lo consideraron como viable la comisión de delitos por la falta de empleo. En otras palabras, si se vive en pobreza y/o desigualdad, el cometer un crimen es justificable, mas no por la falta de empleo.

Se les hizo analizar también la relación existente entre la apertura de nuevos comercios como una solución a disminuir la violencia, esto a raíz del conocido cierre masivo de negocios en la ciudad 


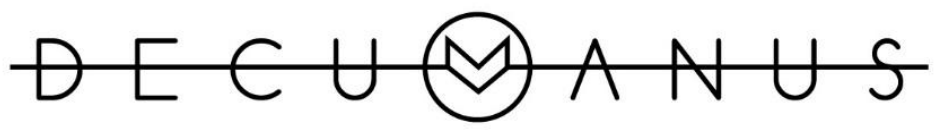

REVISTA INTERDISCIPLINARIA SOBRE ESTUDIOS URBANOS

como resultado de la violencia a raíz de la lucha por la plaza entre los carteles de la droga en la cual el $42 \%$ de ellos lo consideró viable, sin embargo, uno de ellos contestó que por el contrario, la apertura de comercios aumenta la violencia, debido a que hay más lugares y gente de las cuales aprovecharse.

Al hacer una semblanza y explicarles sobre lo que es el equipamiento urbano (calles pavimentadas, banquetas en buen estado, alumbrado público, postes, bancas, etc.) y su liga con la violencia, el $50 \%$ de ellos manifestaron que sí existe una liga relacional entre ambos, y solo uno consideró que no tiene ninguna relación con la violencia existente el que haya, por ejemplo, banquetas en buen estado, alumbrado público, etc.

Del mismo modo se les pidió consideraran la relación educación y violencia, de la que el 58\% consideró que, a mayor educación, menor posibilidad de cometer un delito, dos de ellos consideraron que no existe ninguna relación y el 33\% de ellos consideraron posible según el caso, la existencia de tal relación. Al continuar con el tema de educación se les cuestionó su parecer acerca de si la deserción escolar favorece en cierta medida a que dichos jóvenes se incorporen o sean presa fácil para incorporarse a grupos criminales en donde el 58\% de ellos respondieron afirmativamente, incluso uno de ellos (el deportado) manifestó claramente un ejemplo en su propio hijo y el resto lo consideró posible.

Se les hizo pensar acerca del espacio en el que se les entrevistó - si lo consideraban un espacio violento, donde solo dos de ellos lo consideraron como tal, contrastando con la respuesta de ellos mismos acerca de si se sienten vulnerables a la violencia, por lo que podemos percibir que existe una diferencia entre la percepción del miedo (carácter subjetivo) y la apreciación sobre el espacio físico (carácter objetivo). Se les preguntó si existía la posibilidad de una ciudad sin violencia o si toda ciudad lleva implícitamente la violencia, el 67\% de ellos contestaron que no hay ciudad sin violencia.

También se les cuestionó acerca de si para evitar ser motivo de algún acto violento habían modificado su apariencia, conducción (andar) o hasta la visita a ciertos EP en la ciudad en donde el $58 \%$ de los entrevistados contestó que sí, sí han modificado en algo, su andar por la ciudad. Al ser hombres los entrevistados, se les cuestionó si consideran que los espacios públicos son territorio de hombres o dominado por hombres como es el discurso mediático común, solo dos de ellos (17\%) lo consideró así, en contraste con el resto lo considera un espacio mixto e incluso familiar.

Por último, se les preguntó de manera directa si tenían miedo a salir, en donde el 25\% contestó afirmativamente y solo uno de ellos lo consideró posible, mientras que el resto contestó tajantemente que no tenían miedo a salir, no importaba el lugar ni la hora. En este aspecto vale hacer una diferenciación entre la respuesta directa a la pregunta y la respuesta hecha al final de la entrevista, en 


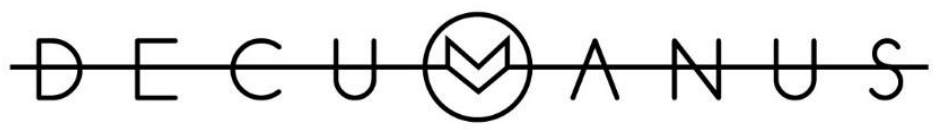

REVISTA INTERDISCIPLINARIA SOBRE ESTUDIOS URBANOS

la que, en este último momento, la gran mayoría aceptó tener miedo a salir, lo anterior al exponerles un escenario posible en el cual, su vulnerabilidad se veía comprometida.

A manera de conclusión de la observación de los datos cuantitativos recabados a raíz de las entrevistas, podemos apuntar que: en general y a pesar de que algunos han sido víctimas de algún tipo de delito a lo largo de su vida, el hombre adulto en CJ no tiene miedo a salir ni percibe su andar como un espacio violento al momento de la entrevista (caso contrario en el periodo violento mencionado con anterioridad), aunque si modifica su conducta y apariencia para evitar ser víctimas del crimen. No conoce en general el concepto de la vulnerabilidad, pero sí se siente vulnerable ante la violencia. Contrario a lo que se comenta comúnmente, por lo menos en CJ, los hombres no se consideran dueños del EP, por el contrario, lo perciben como un espacio de convivencia para todos, inclusive para visitarlo con los miembros de su familia. Existe una marcada geografía de la violencia y del miedo, es decir, todos en general manifestaron evitar ciertos lugares a ciertas horas y por consecuencia perciben miedo a salir, por lo menos a dichos lugares. Tanto la educación, como la pobreza y la desigualdad, la infraestructura urbana y su equipamiento, así como la apertura de comercios es decir el desarrollo económico, son elementos clave para los entrevistados en la relación de los mismos con actos delictivos cometidos en el EP.

\section{Análisis de los Datos Cualitativos}

En este apartado se expone a manera de narrativa, extractos de las experiencias vividas por los entrevistados tratando de ligarlas con argumentos de autores que han abordado el tema. Se analizará mediante la experiencia de vida del(os) entrevistado(s), cuatro casos cuyos títulos resultan de frases expresadas por ellos mismos, una por eje temático (Espacio Público, Masculinidad, Miedo y Temor, y Violencia Urbana). Vale la pena hacer mención de la importancia de su voz, expresada muchas veces con dolor, con frustración, pero de igual manera con resignación y hasta con un cierto positivismo ante la realidad juarense. A todos los entrevistados muchas gracias por compartir parte de su vida para la elaboración de este apartado.

\section{Si Vas A Un Lugar (EP) Y Está Cuidado, Te Da Seguridad}

El concepto de sentido de lugar (sense of place) aparece para explicar muchas de las formas en que la gente se relaciona con el lugar; como tal es parte de un cuerpo literario dirigido a aspectos emocionales, simbólicos y espirituales (Cighi, 2008). Si existe la topofilia (amor al lugar), existe entonces la topofobia (miedo al lugar); hemos observado también la agorafobia (miedo al espacio 


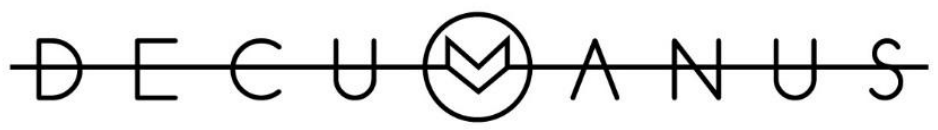

REVISTA INTERDISCIPLINARIA SOBRE ESTUDIOS URBANOS

público). Es entonces cuando podemos hablar de una geografía del miedo, la cual Modly (2009) define como aquel lugar que es percibido por la gente como peligroso o de miedo.

Para entender la geografía del miedo se ha incorporado comúnmente el razonamiento de las "ventanas rotas", analogía que dice que, si una ventana de un edificio se rompe, los residentes deberán repararla a la brevedad posible o los demás asumirán que nadie se interesa por el edificio y comenzarán a arrojar más piedras, rompiendo así más vidrios (Modly, 2009). La ausencia de signos visuales de orden conlleva a mayores índices de crimen (ibíd.). En este sentido los signos visuales de desorden y abandono están inexorablemente ligados a mayores índices de delincuencia. Una reacción común ante imágenes en ruinas de casas o calles es que los habitantes claramente no tienen respeto por el espacio o por el edificio (ibíd.). La lógica común detrás de esta idea es que tales personas irrespetuosas de su entorno, probablemente tampoco tienen respeto hacia otros individuos, lo cual se piensa, llevará a los habitantes a cometer crímenes o a permitir que otros cometan crímenes ahí (ibíd.).

Como te diré si hay, o sea si está ligado eso por ejemplo, el hecho que de una cuadra a otra esté oscuro, pues hay más riesgo de que la delincuencia te pueda atacar o te pueda hacer algo, donde hay una zona que está iluminada está bien identificada, bien pintada es una zona como luego decimos bien cuidada, está protegida, eso te da seguridad en tu entorno verdad? es muy triste por ejemplo, yo vuelvo a decir, camino, corro, ando en bicicleta en este parque y simplemente ahí los monumentos donde se robaron al chavito (escultura) o simplemente cualquier monumento que estén los faros para iluminarlo de noche digamos que está desvalijado ya no tiene los faros pues eso te da hasta cierto punto inseguridad, dices pues ¿dónde ando? pues a lo mejor no está tan seguro pero pues eso es lo que te proporciona el gobierno, pero ya la delincuencia se encarga de destruirlo, yo pienso que sí es indispensable si vas a un lugar, está cuidado, te da seguridad el estar ahí, cómodo, y si vas a un parque y ves que está la basura, no se hay mucha basura o no hay botes de basura, está tirado, está destruido, pues lógicamente te da inseguridad ... (Ingeniero)

Al incorporarse un nuevo marco analítico como el expuesto por Modly (2009), se demuestra que las estadísticas del crimen no son los factores principales que producen el miedo; de hecho, muchos otros factores parecen tener un mayor impacto en la apreciación sobre lugares seguros y peligrosos entre las personas. Como resultado de la percepción que los entrevistados manifestaron en relación a las condiciones físicas del entorno que circulaban, pude observar que la mayoría de ellos 


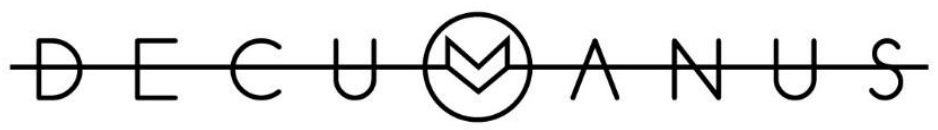

REVISTA INTERDISCIPLINARIA SOBRE ESTUDIOS URBANOS

considera que las condiciones de equipamiento urbano entendido como calles pavimentadas, alumbrado público, bancas en plazas y parques, botes de basura, banquetas que permitan la circulación peatonal entre otras muchas características, favorecen cuando éstas se encuentran funcionando en buen estado a reducir los índices de criminalidad o específicamente para reducir la posibilidad de ser asaltado o violentado en su integridad y/o en sus pertenencias personales, y como consecuencia a sentirse seguros.

\section{Eso Si Soy Bien Peleonero}

La antropología desde siempre se ha ocupado de hombres hablándole a hombres sobre hombres; sin embargo, hasta hace poco tiempo, fueron contados aquellos quienes dentro de la disciplina del estudio del hombre realmente examinaron a los hombres como hombres (Gutmann, 1998). Los nuevos análisis sobre los hombres como sujetos con género y que otorgan género constituyen actualmente la antropología de la masculinidad (ibíd.).

En numerosas ocasiones se ha reiterado que la violencia constituye un elemento identitario de los hombres; también puede considerarse que la acción violenta tiene un sentido específico en la construcción de la identidad masculina de los jóvenes, por ello, tal búsqueda que muchos jóvenes inician a edades tempranas va ligada con las prácticas sociales de violencia como forma de adquirir un aprendizaje que lleve o acerque al modelo de masculinidad dominante (Cruz Sierra, 2014). El homicidio masculino, como una expresión de la violencia social y urbana, pero particularmente como una acción humana matizada por el género, da cuenta de una subjetividad que adquiere como principal rostro el masculino y como característica principal la violencia; violencia masculina producto de un proceso histórico, cultural, social y económico que, incrustado en el cuerpo social, se concreta en los cuerpos de hombres que mediante determinadas prácticas sociales ostentan no solamente ejercicios de poder que acaban con la vida de otros hombres, sino también con su propia vida (ibíd.).

De día! y todavía así llegue a la Cruz Roja como pude, como pude, sangrando, como pude todo golpeadote, no miraba de lo hinchadote de los ojos, no miraba nada, miraba así muy apenitas una rayita, ya ves cuando está uno ... se te cierra el ojo así verdá? pidiendo ayuda y nadie-nadie, tenían miedo a que me fuera a morir, pero me acuerdo muy bien de su nombre de ese chavo, y me acuerdo muy bien donde vive, me acuerdo muy bien de todo, de donde salieron, todo, de donde salió la mamá y le dijo: ey baboso que estás haciendo? y el acá, usted métase! y acá y allá y sacó la daga y cuando volteé, yo que quise correrle, me apeñugó de aquí [indica la parte trasera del cuello de la camisa] me la hizo así y me la enterró en la espalda, y tras! ya nomás vi que me salió, si me entiende? y 


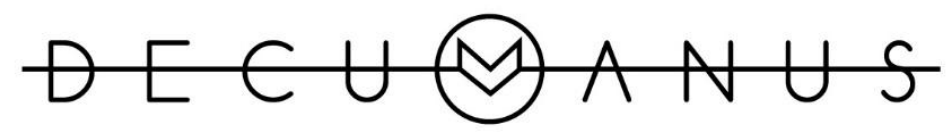

REVISTA INTERDISCIPLINARIA SOBRE ESTUDIOS URBANOS

ya no me acuerdo más que cuando me estuvo golpee y golpee, o sea me desmayó a golpes! en cuanto abrí los ojos, ya no lo vi ahí y veo nomás que se estaban asomando por la ventana, me fui gateando hasta la Cruz Roja donde está Zaragoza, hasta ahí, ahí fue donde llegué, y ya pedí el auxilio, me dieron el auxilio, me trajeron al Hospital General, ahí me operaron y todo eso, ahí fue donde me curaron y todavía así sin embargo, pos nos cobraron, tuvo que venir mi madre [de Chihuahua] y pagó \$18,500, pagó ajá, si pos me reconstruyeron un riñón! si me entiendes? y un istentino [intestino], un istentino, un pulmón si porqué me picó! me puso cuatro piquetes, me puso cuatro piquetes el bato! y o sea, me hubiera pedido! se la hubiera dado! [el dinero/la feria], me hubiera dicho eso, pos tenga, ahí le va, no hay pedo, pero como me va a hacer ese jale? y el bato, todos le tienen miedo, dicen que todos le tienen miedo ahí, que es una persona peligrosa, que quien sabe ... (relato de asalto del Deportado)

En términos generales, la violencia urbana se encarna en el rostro masculino apunta tácitamente Cruz Sierra (2011), y bajo la pregunta acerca de ¿por qué los hombres participan más del crimen homicida? nos responde: se ha observado que el homicidio masculino está asociado con la rivalidad, la competencia frente a los pares, la demostración de la superioridad frente al otro y, al parecer, el hombre, podría matar con mayor frecuencia en donde el tejido afectivo es mínimo; la práctica del homicidio, en tanto acto de extrema violencia, se relaciona con la identidad masculina, o al menos se asimila a rasgos atribuidos a ciertos modelos de masculinidad dominante (Cruz Sierra, 2011). Aunque no existe una relación directa entre estos dos elementos, ni se pretende plantear la violencia como elemento definidor de la masculinidad o se piense en todo hombre como un homicida potencial, sí resulta relevante pensar en la predisposición de algunos hombres al ejercicio de la violencia o al homicidio, dadas sus biografías e historias personales, además de las condiciones socioculturales que las posibilitan.

\section{Habiendo Entrada Paso... No Le Hace Que Esté El Demonio, Hablo Con Él}

En las últimas décadas, el cine y la televisión han sido promotoras de un protagonista principal: la violencia. Este tipo de espectáculo, contribuye a desnaturalizar el fenómeno; la estética de la violencia cambia la visión de entretenimiento de las personas, especialmente la de los jóvenes; películas, videos musicales y hasta dibujos animados, tienen como foco la agresión y la intrepidez por parte de sus protagonistas. Este es el mundo donde han nacido y crecido nuestros jóvenes nos comenta Silva 


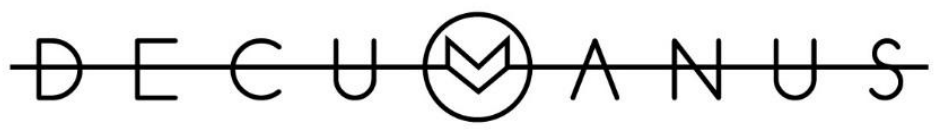

REVISTA INTERDISCIPLINARIA SOBRE ESTUDIOS URBANOS

(2006); adolescentes y niños e incluso hasta adultos, se encuentran socializados por la televisión y los juegos de video ante la mirada impávida de otros adultos que los demonizan, los estigmatizan, los utilizan, pero no dan soluciones a problemas concretos, convirtiéndose en cómplices de una situación que se nos escapa de las manos.

El miedo al delito trasciende las relaciones personales, aunque no necesariamente disminuye su bienestar; es considerado como una defensa natural y adaptativa contra el crimen, así, observamos la distinción entre la preocupación disfuncional que altera la calidad de vida y la preocupación funcional que motiva la vigilancia y la precaución (Muratori \& Zubieta, 2013). El miedo de los ciudadanos tiene un fundamento real en el incremento del crimen violento, pero es también imaginario nos dice Briceño León (2007). El fantasma de la violencia se agiganta con las fantasías de las personas y se iguala en su angustia compartida (ibíd.); por eso, en ciudades o en zonas de la ciudad en donde la violencia no es particularmente grave, el temor adquiere las mismas magnitudes que donde si representa una fuerte amenaza; por ello la seguridad ciudadana es un hecho real y es un sentimiento - declara Briceño León (2007).

En contraposición a lo expuesto por Silva (2006) acerca de la influencia mediática en relación a la violencia, Briceño León (2007) puntualiza que el miedo no es el producto de una ficción creada por los medios aunque en algunos casos y zonas, los temores pueden parecer exagerados y atribuidos al escándalo de la noticia, sino que es el resultado de una situación real que se vive de manera personal o vicaria (historias de amigos o familiares) e incluso aquellas referidas de casos reales en los medios de comunicación. El temor es entonces según Oviedo (1995), producto de una percepción de exposición constante a acciones de violencia delictual, es también un fenómeno social que manifiesta peligro para el bienestar colectivo. Dicho temor tiende a reforzar posiciones poco meditadas, no consensuadas y erradas; el miedo prolongado conduce muchas veces a la adopción de medidas desafortunadas que pone énfasis en la represión sobre otras soluciones, institucionalizando así, la violencia. La excesiva represión conduce a dos situaciones particulares: la primera, a una privatización de la vida, y la segunda a una minimización de su relevancia o a la negación de su existencia (ibíd.).

Mientras que la toma de riesgos y las declaraciones de intrepidez e invulnerabilidad son ampliamente practicadas y normativas de la hegemonía masculina, las estadísticas de crimen indican que la distribución del riesgo al crimen violento es altamente desigual, inclinando la balanza en contra de los hombres (Dammert et al., 2004). El macho hegemónico es reconocido discursivamente por prácticas de agresión e intrepidez, fuerza física y emocional, control y toma de riesgos, así como aquellas cualidades consideradas masculinas o no femeninas que sostienen y reproducen los beneficios materiales del poder patriarcal (Dammert et al., 2004). 


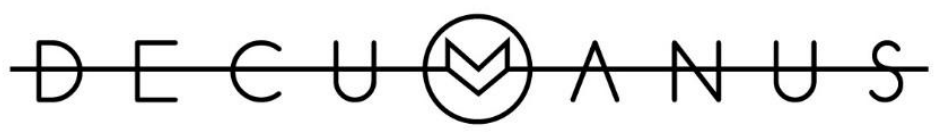

REVISTA INTERDISCIPLINARIA SOBRE ESTUDIOS URBANOS

Un ejemplo que comprueba lo anterior es el que da título a este apartado: "Habiendo entrada paso... no le hace que esté el demonio, hablo con él”, frase expuesta por el entrevistado llamado "Parquero", el cual manifiesta haber pertenecido a la milicia mexicana, la cual, lo entrenó a enfrentar situaciones de peligro en las que debía mostrarse sin ningún temor a pernoctar o a transitar por cualquier lugar, independientemente del entorno, el clima existente o las condiciones. Al igual que este tipo de actitudes intrépidas - sin miedo, se suman otras conductas, por ejemplo, al mostrar una gran capacidad de soportar grandes cantidades de alcohol, así como el abuso de las drogas y los enfrentamientos físicos (peleas), comunes entre este tipo de machos, sobre todo cuando hacen uso y abuso de las anteriores sustancias.

\section{La Mayoría De Los Delincuentes Son Puros Menores De Edad}

El problema de la violencia juvenil ha sido abordado sistemáticamente por la sociología, la criminología, la psicología y otras disciplinas jurídicas, ya que siempre ha llamado la atención de los estudiosos e interesados por los problemas sociales nos dice Pueyo (2004). La violencia se encuentra en casi todos los ámbitos de la vida de los jóvenes: la escuela, el ocio, la familia, el trabajo y también en las relaciones personales, en la vida comunitaria y en la salud (ibíd.). Las conductas violentas no son instintivas ni respuestas automáticas o involuntarias; en la violencia se implican conductas complejas, voluntarias y que tienen una finalidad que puede ser controlar a otros, obtener beneficios, etc. (Pueyo, 2004).

En este sentido diferentes autores nos dan su punto de vista en relación al binomio jovenviolencia. Nos dice Briceño León (2007), "la violencia es un asunto de jóvenes", se estima que el $28.7 \%$ de todos los homicidios que ocurren en América Latina tienen como víctimas jóvenes entre 10 y 19 años de edad. La violencia juvenil ocurre de una manera muy especial al iniciarse la adolescencia alrededor de los 13 años de edad; es el momento en el cual el joven comienza a tener pretensiones de adulto pero muy pocas capacidades sociales de comportarse como tal; es una edad donde comienzan las dificultades de los estudios y muchos abandonan la escuela, pero no tienen edad legal ni preparación técnica para trabajar; éste es un grupo de jóvenes que ni estudia ni trabaja (ninis) ${ }^{3}$ y que se está en gran riesgo de caer en la violencia (ibíd.).

Por su parte, Carrión M. (2008) nos dice que la situación es más dramática si se tiene en cuenta que en AL los jóvenes (grupo poblacional entre 15 y 25 años) son los principales actores, en

\footnotetext{
${ }^{3}$ Acrónimo pegajoso, como pocos, el de los NiNis (o jóvenes que ni estudian ni trabajan) es un término que se ha posicionado con éxito notable en la prensa y medios de comunicación. Es una traducción de la voz NEET o Neet (Not in Employment Education or Training) utilizado por primera vez en 1999 en un informe de la Social Exclusion Unit, que es una oficina de apoyo al gabinete del primer ministro de la Gran Bretaña. Fuente: http://www.inegi.org.mx/RDE/RDE_08/RDE_08_Art6.html
} 


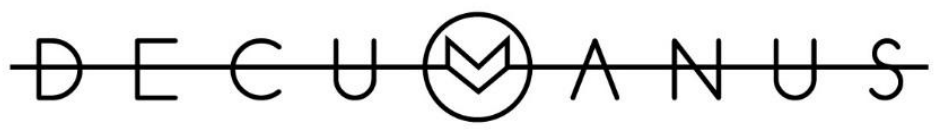

REVISTA INTERDISCIPLINARIA SOBRE ESTUDIOS URBANOS

cuanto agentes de las violencias y víctimas principales; incluso, el título de este apartado es una expresión dada por un agente de la policía municipal, el cual manifiesta categóricamente, que al menos desde su experiencia, "la mayoría de los delincuentes son puros menores de edad"; ello significa que nuestra juventud se merma moral y cuantitativamente; lo cual repercutirá en el futuro del país. De igual manera Cruz Sierra (2014) citando a (García e Ito, 2009) comenta que la categoría hombre joven es producto de la intersección del género, la sexualidad, la clase, la etnia y la edad, y tiene como eje articulador el poder. Dichas categorías se entrecruzan y se asocian con atributos que, en conjunto, se amalgaman y diluyen en un ejercicio cotidiano de hacerse hombre en el mundo de la calle, de la pandilla, de la banda y del grupo de pares; es un proceso siempre inconcluso que tiene sus bases en los lazos primarios del infante con las figuras paterna y materna, y se engrosa con la precariedad y la penuria económica, social y cultural en que éstos niños crecen (Cruz Sierra, 2014).

Por otro lado, observamos que el aspecto de deserción escolar es uno de los problemas más graves en cuestión a la violencia juvenil, situación que se empata con la pregunta hecha por mi parte acerca de: ¿En qué posición se/te encuentra(s) en la premisa de que la deserción escolar es un factor determinante en los jóvenes para incorporarse a los grupos criminales? de la cual, la mayoría de los entrevistados respondieron afirmativamente al considerarlo un detonante principal de liga con el crimen.

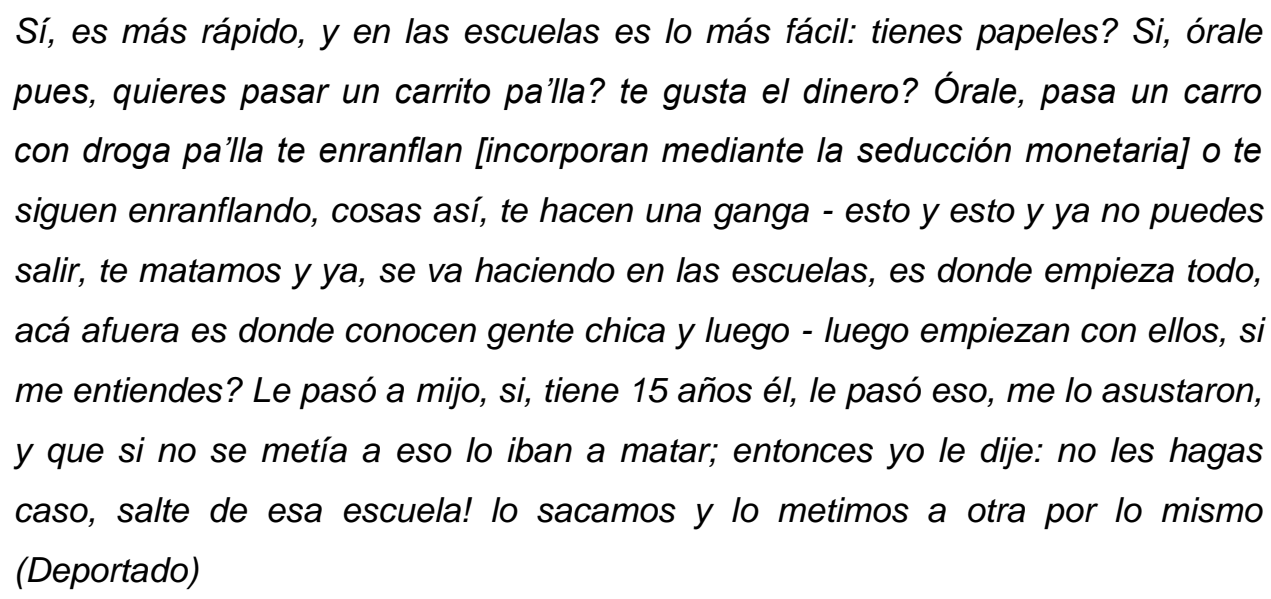

De acuerdo a estudios citados en el análisis publicado en junio de 2012 por el Banco Mundial "La Violencia juvenil en México", los jóvenes mexicanos representan un poco más del 38\% de las víctimas de homicidios en el país en la última década. La tasa de homicidio juvenil se triplicó en solamente dos años (2008 a 2010) al llegar a 25.5 homicidios por cada 100,000 habitantes; además, el uso de armas de fuego en homicidios juveniles casi se triplicó entre 2007 y 2010 . El homicidio de 


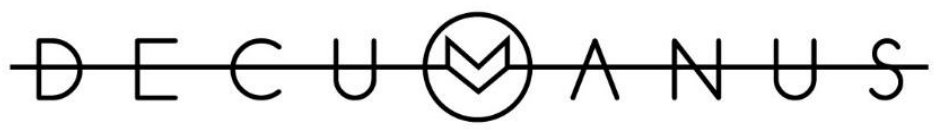

REVISTA INTERDISCIPLINARIA SOBRE ESTUDIOS URBANOS

jóvenes se ha concentrado en el norte del país según el informe; en el 2010, más de la mitad de los homicidios ocurrieron en 5 estados: Chihuahua, Sinaloa, el Edo. de México, Baja California y Guerrero.

Según este informe, una de las principales causas del aumento de la violencia ha sido las disputas entre organizaciones criminales dedicadas al narcotráfico; aunado a esto se encuentra en dicho informe que los jóvenes no han sido solamente las víctimas, sino también la mayoría de los agresores. Más de la mitad de los delitos en 2010 se cometieron por jóvenes; de estos jóvenes, la mayoría tenía entre 18 y 24 años de edad, y casi todos, 9 de cada 10, eran hombres.

De 2008 a 2011, se registraron más de 10,000 asesinatos violentos en Ciudad Juárez; solo 400 de estos correspondieron a mujeres, mientras que el 95\% de las víctimas fueron hombres - en su mayoría jóvenes. El término juvenicidio, si bien se ha empleado para nombrar el asesinato mayoritario de jóvenes en el país, pierde de vista las especificidades de aquellos que han sido víctimas del combate al crimen organizado y de las políticas de seguridad - comenta Cruz Sierra (2014), pues son hombres que corresponden a sectores barriales y vinculados con clicas o gangas juveniles; a la mayoría se les atribuía participación en actividades delictivas; sus características coincidentes eran ser hombres, pobres y estigmatizados, como los llamados cholos (ibíd.).

Más allá del dato estadístico de la población mayormente afectada por la violencia homicida, otra complejidad es enunciar lo juvenil, señala Cruz Sierra (2014). Plantear el tema de los jóvenes, específicamente hombres jóvenes, en su participación en la violencia social, en cuanto a sus prácticas gregarias, uso social de drogas, utilización del tatuaje, bailes, grupos musicales, su representación estético-social anclada en el cuerpo, su identidad como jóvenes y hombres, su grupo de pares y su posición en la sociedad, uso del tiempo libre, su vínculo con las instituciones sociales, así como su participación en prácticas de violencia, resulta en un enmarañamiento de factores (Cruz Sierra, 2014), mismos que deberán tratarse como parte de un todo llamada violencia juvenil.

\section{Conclusión}

Como hemos visto a lo largo de este texto, los estudios acerca de los hombres se han obviado y algunas veces se han invisibilizado, tal vez por decisión propia de éstos mismos para mantenerse fuera del escrutinio público. Las constantes asunciones y afirmaciones sobre la supuesta intrepidez e invulnerabilidad de los hombres sobretodo en la esfera pública, han creado un discurso social y muchas veces académico casi universal. Encontrar la razón del porqué de la violencia masculina, sigue siendo motivo de encuentros y discrepancias entre los diferentes autores que abordan el tema, siendo el aspecto de la socialización el más aceptado para atribuir su origen, es decir, se aprende a ser violento a partir de la convivencia y el aprendizaje en sociedad y desde la niñez; este aprendizaje 


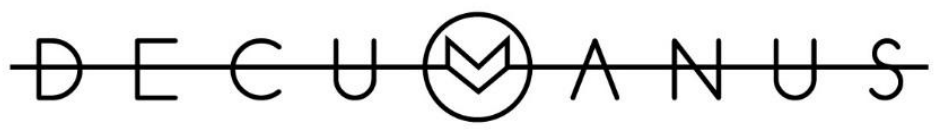

REVISTA INTERDISCIPLINARIA SOBRE ESTUDIOS URBANOS

casi forzado de convertirse en un verdadero hombre, genera en el niño/joven, sentimientos de impotencia y rabia cuando se enfrenta a cumplir con las reglas no escritas por la sociedad, sobre todo cuando éste individuo no posee las características que le son demandadas dando como consecuencia una crisis de masculinidad.

Considero que el resultado más relevante en esta investigación es el que establece que la violencia es cosa de hombres, pero de hombres jóvenes; son éstos los que en aras de construir su identidad masculina a través de la socialización, se ven envueltos en diferentes conflictos que, sumados a factores de marginación y desigualdad, concluyen en actos violentos perpetrados en muchos casos en el espacio público, dando como resultado que las estadísticas de mortalidad y de lesiones corporales, coincidan incluso en diferentes geografías, en precisamente ellos, los hombres jóvenes y marginados. Si a esto le sumamos que en contraste con lo comúnmente asumido acerca de la maximización de la longevidad, es decir vivir lo más posible, se le superpone la perpetración de la especie, es decir, dejar huella de su masculinidad al procrear hijos y reiterar su hombría mediante actos performativos, nos deja como consecuencia una alta propensión a la violencia. De similar importancia es el hecho de refutar el supuesto privilegio que el hombre goza por el simple hecho de ser hombre, ya que tal privilegio solo es disfrutado por una pequeña parte de la población masculina (clase media o alta, heterosexual y con ciertas características físicas), incluso los homosexuales carecen de todo privilegio en este sentido.

Es pues en resumen y a manera de contra-narrativa al discurso social y académico, se demuestra que el hombre también tiene miedo a salir a la calle (aunque no siempre lo manifieste); también es víctima de la violencia urbana; también es protector de sus más allegados y no solo es el perpetrador de la violencia como se ha querido estigmatizar; que los índices de mortalidad y de riesgo a ser víctimas de un crimen o delito se inclinan en desventaja hacia ellos - los hombres, especialmente hacia la población joven y marginada, muchas veces en radios de comparación altamente desiguales y sin el reconocimiento social; que su supuesta intrepidez (ausencia de miedo) no es tal; y que todos los miembros de la sociedad contribuyen e influyen en gran medida bajo una presión social que surge desde la niñez a la formación de su masculinidad, su identidad y su género, y que, como he manifestado: son parte de la otra vulnerabilidad.

\section{Bibliografía}

Aramburu, M. (2008). Usos y significados del Espacio Público. Architecture, City, and Environment, III, 143-149. 




REVISTA INTERDISCIPLINARIA SOBRE ESTUDIOS URBANOS

Augustus, R. (2015). To be a man. A guide to true masculine power. Sex, power, and the journey to full manhood. Boulder, CO: Sounds True.

Blazina, C. (2003). The cultural myth of masculinity. Westport, Conn.: Praeger.

Borja, J. (1998). Ciudadanía y espacio público. [

Ciutat real, ciutat ideal. Significat i funció a l'espai urbà modern ] Urbanitats, (7)

Borja, J., \& Muxí, Z. (2000). El espacio público, ciudad y ciudadanía [L'espai públic: ciutat i ciutadania.]. Barcelona: Electa.

Bribiescas, R. G. (2006). Men: Evolutionary and life history. Cambridge, Mass.: Harvard University Press.

Briceño León, R. (2007). Violencia urbana en América Latina: Un modelo Sociológico de Explicación. Espacio Abierto Cuaderno Venezolano de Sociología, 16(3), 541-574.

Brittan, A. (1989). Masculinity and power. Oxford, UK; New York, NY, USA: Basil Blackwell.

Brownlow, A. (2005). A geography of men's fear. Geoforum, 36, 581-592. Retrieved from www.elsevier.com/locate/geoforum database.

Carrión M., F. (2008). Violencia urbana: un asunto de ciudad. Revista Eure, XXXIV (103), 111-130.

Cighi, C. I. (2008). Senses of place. (Master's Thesis, University of Massachusetts).

Cruz Sierra, S. (2011). Homicidio masculino en Ciudad Juárez. Costos de las masculinidades subordinadas. Frontera Norte, 23(46), 239-262.

Cruz Sierra, S. (2014). Violencia y jóvenes: pandilla e identidad masculina en Ciudad Juárez. Revista Mexicana de Sociología, 76(4), 616-637.

Cruz, J. M. (1999). La victimización por violencia urbana: niveles y factores asociados en ciudades de América Latina y España. Revista Panamericana de Salud Pública, 5(4), 259-267.

Dammert, L., Karmy, R., \& Manzano, L. (2004). Ciudadanía, Espacio Público y Temor en Chile. Chile: Centro de Estudios en Seguridad Ciudadana de la Universidad de Chile.

Fernández-Ramírez, B. (2008) Seis hipótesis de trabajo para entender la delincuencia y el miedo al delito. Revista Española de Investigación Criminológica, 6, 1-25.

Gutmann, M. C. (1998) TRAFICANDO CON HOMBRES: La Antropología de la Masculinidad. Revista de Estudios de Género, La ventana, 47-99. Retrieved from http://www.redalyc.org/articulo.oa?id=88411133004; database.

Kaufman, M. (Ed.). (1987). Beyond patriarchy: Essays by men on pleasure, power and change. Toronto; New York: Oxford University Press. 




Modly, A. R. (2009). Geography of fear: Understanding students' sense of place. Annual Review of Undergraduate Research, School of Humanities and Social Sciences, School of Languages, Cultures, and World Affairs, College of Charleston, 8, 115-146.

Muratori, M., \& Zubieta, E. M. (2013). Miedo al delito y victimización como factores influyentes en la percepción del contexto social y clima emocional. Boletín de Psicología, (109), 7-18.

Oviedo, E. (1995). LA VIOLENCIA URBANA (Boletín del Programa de Pobreza y Políticas Sociales de SUR No. 7). Chile: TEMAS SOCIALES 7.

Pueyo, Antonio Andrés. (2004). Violencia juvenil: realidad actual y factores psicológicos implicados. Universidad de Barcelona.

Salazar Gutiérrez, S. (2016). Vida y castigo: Jóvenes en prisión sentenciados por homicidio en Ciudad Juárez, México. Estudios fronterizos, 17(33), 1-15. Recuperado en 04 de septiembre de 2016, de http://www.scielo.org.mx/scielo.php?script=sci_arttext\&pid=S0187$69612016000100001 \& \operatorname{lng}=e s \&$ tlng=es.

Silva, A. (2006). La cultura de la violencia: la transgresión y el miedo de los adolescentes. FERMENTUM, 16(47), 664-674.

LA VIOLENCIA JUVENIL EN MÉXICO. Reporte de la situación, el marco legal y los programas gubernamentales (2012). (Documento preparado por el Equipo para la Prevención de la Violencia (Departamento de Desarrollo Social) y el Equipo de Seguridad Ciudadana para Latino América y el Caribe del Banco Mundial. EL BANCO MUNDIAL. 